\section{SOME OBSERVATIONS ON THE}

\section{DIASTASE REACTION OF THE URINE.}

BY ARTHUT F. SIAADDFN, D.M., B.Ch. OXF., DIRECTOR OF BECK LABORATORY, SWANSFA GENERAL HOSPITAL.

THE measurement of the diastatic activity of body fluids, particularly of the urine, has been applied to clinical purposes for about ten years. It was originally introduced by Wohlgemuth 1 as a means of diagnosis in pancreatic disease ; later (1913) it was shown by the late Dr. Dudley Corbett ${ }^{2}$ that whereas in pancreatitis the urinary diastase tended to be increased above normal, conversely in presence of renal lesions the excretion of diastase in the urine was usually diminished. The majority of workers on this subject have adopted Wohlgemuth's technique, of which descriptions are now available in several text-books. After considerable experience of the method, I wish to advocate an improvement in this technique, simple but particularly important when renal efficiency is in question.

Wohlgemuth, for reasons which will be indicated later, laid no stress on the need for adjusting the acidity of the urine to a standard before testing. Corbett, in his study of the subject, stated that variations in the reaction of the urine were not of importance, and Mackenzie $\mathrm{Wallis}^{3}$ apparently concurs in this opinion. I, however, cannot agree that the hydrogen-ion concentration $(\mathrm{pH})$ is a negligible factor in the technique, especially when the technique is applied to measure quantities of diastase at the lower levels, as in cases of renal inadequacy. The optimum $\mathrm{pH}$ for the diastatic enzyme in presence of chloride is given by Walpole ${ }^{4}$ as $6 \cdot 7$. Cole in his textbook notes the fact that adjustment of $\mathrm{pH}$ in the determination of diastase is desirable, nevertheless the usual Wohlgemuth procedure without this precaution is described for use in routine work.

An accurate adjustment of the hydrogen-ion concentration in all the tubes of the test would require (1) adjustment of urine $\mathrm{pH}$ to $6 \cdot 7$ by means of Cole's comparator, and (2) addition of suitable amount of phospnate buffer mixture at $\mathrm{pH} 6.7$ with the starch solution to each tube of test. For practical purposes, without employment of the comparator method, a sufficient degree of accuracy is obtained if the urine be titrated with $\mathrm{N} / 10 \mathrm{NaOH}$ in the presence of phenol red as indicator, the first appearance of a faint pink tinge being taken as end-point corresponding to a pH $6 \cdot 7$. With alkaline urines titration back with $\mathrm{N} / 10$ Hol may be necessary. With regard to $(2)$, the addition of phosphate buffer mixture tends to obscure the reading of final results, so that although by this system the diastase is acting under optimal conditions in every tube of the series, and shows a higher activity than when determined without adjustment of $\mathrm{pH}$, nevertheless the greater difficulty in deciding endpoints introduces an undesirable complication. In practice, therefore, one may omit (2) while retaining (1), simplifying the adjustment if desired.

Of course, when the urine has a high level of diastatic activity the importance of the $\mathrm{pH}$ adjustment diminishes, as the relative quantity of urine in the end-point tube becomes so small. This would usually be so in pancreatic cases, and forms the justification of Wohlgemuth in his neglect of the $\mathrm{pH}$ factor of the urine when using this test for evidence of pancreatic disease. When, however, one is concerned in measuring diastase at the lower ranges, say from 15 units downwards, this factor assumes a real significance, which is accentuated according as the hydrogen-ion concentration of the urine is further removed from the optimum figure, $\mathrm{pH} 6 \cdot 7$.

\section{Influence of Increased Hydrogen-Ion Concentration} on the Reaction.

The average pH for normal urine is given as 6 ; not infrequently it may be considerably further along the acid direction, and with pathological urines may reach $\mathrm{pH} 4$ or eren lower. Palmer and Henderson's have shown that in certain types of nephritis the hydrogen-ion concentration of the urine tends to be especially high (with, of course, correspondingly low $\mathrm{pH}$ exponent figure). The influence of such increased hydrogen-ion concentration is indicated by the following determinations in which the Wohlgemuth test was carried out: (a) with ordinary urine, (b) with urine adjusted approximately to $\mathrm{pH} 6.7$ as described, using phenol red as indicator. The amounts of $\mathrm{N} / 10$ alkali required to bring each sample of urine to $\mathrm{pH} 6 \cdot 7$ is given in Table $\mathrm{I}$.

TABLE I.

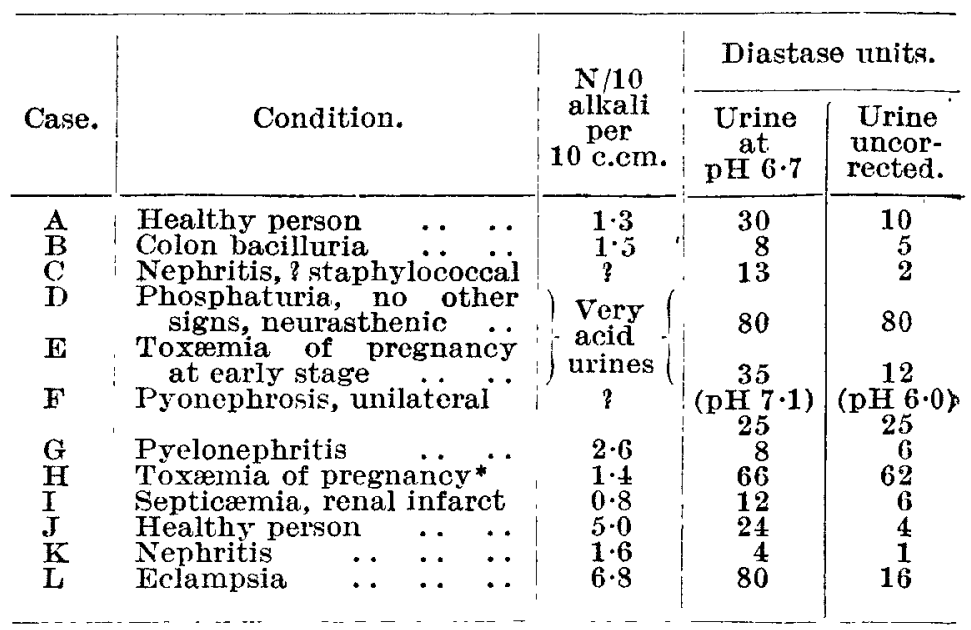

* Case II one day later

It is evident that the diastatic units obtained from the non-adjusted urines gave, in at least half the cases, quite misleading information; whereas the units found in " corrected " urines had, for the most part, a significance which was of diagnostic value. For example, the renal efficiency in Case $C$ was not so impaired as the "uncorrected" unit value would suggest; in Case $J$ there was no reason to doubt the renal adequacy, though the unit value of 4 would have suggested otherwise; and in Case $L$ the evidence for toxæmia would have been missed.

A few experiments were made by testing urines adjusted to various $\mathrm{pH}$ values by means of indicators, all diastase estimations on each urine being carried out in parallel. The existence of an optimum point, and the necessity for working to this point if uniform results are to be obtained, is clearly shown in Table II. The $\mathrm{pH}$ values here are to be taken as only approximate, but sufficiently so for purposes of the experiment.

TABLE II.

\begin{tabular}{|c|c|c|c|c|c|c|c|c|c|c|c|}
\hline \multirow{2}{*}{ Crine. } & \multicolumn{8}{|c|}{ pH ralues. } & & \multirow[b]{2}{*}{$8 \cdot 2$} & \multirow[b]{2}{*}{$8 \cdot 3$} \\
\hline & $3 \cdot 5$ & $4 \cdot 0$ & $5 \cdot 0$ & $5 \cdot 9$ & $6 \cdot 5$ & $6 \cdot 7$ & $7 \cdot 0$ & $7 \cdot 5$ & $8 \cdot 0$ & & \\
\hline (d.u.) & & $1-$ & 4 & 10 & - & 30 & - & - & - & 15 & - \\
\hline $\mathbf{B}$ & 80 & - & - & - & - & - & 80 & - & - & 90 & - \\
\hline $\begin{array}{l}\text { (a.t. }) \\
\text { (d.u.) }\end{array}$ & - & $1 \cdot 0$ & $1 \cdot 5$ & - & $4 \cdot 0$ & - & $6 \cdot 0$ & $5 \cdot 0$ & $2 \cdot 5$ & - & $1 \cdot 0$ \\
\hline
\end{tabular}

$-=$ no test made at the corresponding $\mathrm{pH}$ value.

For practical clinical purposes an estimation of thediastatic power which is within 20 per cent. of the true value is usually sufficiently accurate, but when no adjustment to optimum $\mathrm{pH}$ is made, an error amounting to several hundreds per cent. may easily occur and in this event the test may yield a most misleading indication. Some nephritic urines have an unusually high concentration of hydrogen ions, and, if tested without adjustment, may give very low diastase values-due, in part, not to excessively damaged renal tissue, but to this other factor. It is probable that the true (optimal) diastase value of even a nephritic urine is seldom below 4 units, and if with this method of adjustment a value below 4 is found the indication is correspondingly grave. 
As regards the diagnosis of toxæmias of pregnancy, failure to adjust the $\mathrm{pH}$ of the urine may lead, as in Cases $\mathrm{E}$ and $\mathrm{I}$ (Table I.), to error which entirely vitiates the value of the test. It is consequently suggested that this adjustment to standard $\mathrm{pH}$ value is essential if the test is to give consistent and useful results.

Another point of importance in the utilisation of the diastase test is the need for correlating the unit value found with the urinary output in a 24-hour period, just as one has more regard for the daily output of urea or of glucose than for an isolated percentage estimation. Both these factors tend to increase the range and utility of the test, and at the same time they hardly involve any extra time or trouble in performance.

\section{Features of the Technique.}

It is hardly necessary at this stage to give a full account of the technique of the test ; this is available in text-books to which reference is made. The following features may, however, be noted : 1. Adjustment of urine to $\mathrm{pH} 6 \cdot 7$, as already described. 2. Use of a 1 : 20 dilution of stock starch solution ( 2 per cent. starch in 10 per cent. NaCl solution), as advocated by Mackenzie Wallis and by Cole. 3. Use of distilled water for all dilutions. 4. When possible use of a sample from a 24-hour collection of urine, and the consideration of the total day's output in assessing the result.

A short survey of tests made in nearly 100 cases recently will serve to show how far the method has practical application and utility and will indicate also its limitations. The tests are grouped here according to unit values found, and the clinical nature of the cases examined is noted. D.u. = diastase units.

Units 5 to $10: 21$ estimations.

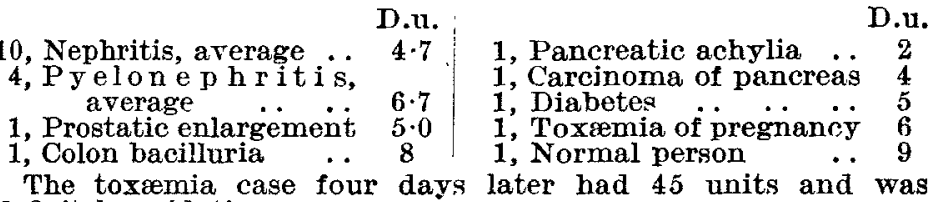

The toxæmia case four days later had 45 units and was definitely acidotic.

Units 10 to 15 : 16 estimations. D.u.

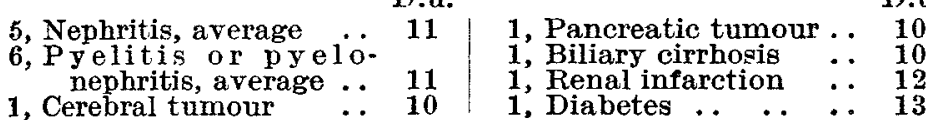

Units 15 to $20: 6$ estimations.

2, Pyelitis or pyelanephritis, average .. 18

1, Chronic nephritis $\quad \therefore \quad 16$

1, Cystitis (staphylo: coccal) 18

Units 20 to $25: 14$ estimations.

D.u. ।

3, Normal persons, average

2 , Prelonephritis, average

Nepbritis

1, Post-partum cystitis ..

Units 30 to 40 : 5 estimations. D.u.

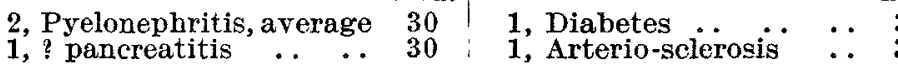

1. Aplastic a $\mathrm{n} æ \mathrm{~m}$ i a (with pregnancy).

1 , Normal person...

3

Units 40 to $60: 14$ estimations.

\begin{tabular}{lc|c} 
D.n. Pyelonephritis, average & 43 & 1 , Pyrexia with acidosis
\end{tabular}

, Cystitis, average

2, Toxæmia of pregnancy, average

1, Biliary cirrhosi (? with pancreatitis) 1, Carcinoma of pylorus (with glycosuria) .. 50

1, Nephritis . Nephritis, puerperal $\ldots \quad 40$

Units 60 or above : 11 estimations.

6 , Toxæmia of pregnancy, D.u.
80

2, Gi ycosuria, slight, average

2, Pyelitis of pregnancy

1 , Pyelonephritis 666 \& 60 $90 \quad 1$, Phosphaturia $\ldots . \quad \ldots 80$ Inorganic phosphates have previously been observed by Löb ${ }^{8}$ to cause increases in diastatic output.

A comparison of these findings with those made by other workers using non-adjusted urine shows, as would be expected, higher average unit values. By this standardised system the normal range of diastase values lies between 10 and 40 , and it is probable that if the total daily output of diastase were ascertained as a routine the somewhat extensive width of the normal range would be narrowed.

Values of 6 or less have not been found except in presence of renal disease ; in fact, any urine having less than 10 units, unless the day's total volume be unusually high, is likely to have come from a "renal" subject.

\section{Effects of Various Conditions on Diastase Output.}

Cystitis, pyelitis, and pyelonephritis of definite bacterial causation seem to produce little or no effect on the diastase output. In the event of a nephritis of this kind showing progressively less diastase in a series of estimations the indication is serious. The increase of diastase in the recovery stage of a case of acute nephritis is frequently very striking from the way in which it reflects the clinical improvement.

Cases of pancreatitis or other lesions of this gland have not been numerous enough to allow many estimations. Three cases, however, are noteworthy as showing subnormal diastase values-two tumours of pancreas had respectively 4 and 10 units, and a case of pancreatic achylia, very fully investigated, had 2 units only. Nevertheless, it remains probable that in inflammatory conditions of the pancreas a high diastatic value is the rule, and in any undoubted "pancreas" case which has a low D. excretion, tumour or atrophy may fairly be suspected rather than inflammation. It is suggestive that many diabetics, in spite of an unraised unit value, have a very definite increase in total units excreted in 24 hours.

For aiding in the differentiation of toxæmia of pregnancy from pyelitis or nephritis in pregnancy, the test is most valuable. In the milder cases of toxæmia the changes in diastase excretion afford an index to the progress of the condition, and when surgical intervention is in question a survey of the daily excretion of diastase yields important aid in determining the course of action. Where evacuation of the uterus has to be done a sharp fall in diastase units occurs after about two days.

The test has occasionally been applied to ureteric specimens with a view to estimating the relative efficiency of either kidney; no important degree of difference between the two samples was found, but this is probably associated with the frequent observations that bacterial infections in the kidneys, except when very profound, do not affect the diastatic outflow materially. The presence of methylene-blue in such samples does not interfere to any great extent with the action of diastase.

\section{Summary.}

1. Urines tested for diastatic activity should be brought to a standard hydrogen-ion concentration, preferably the optimum, pH 6.7.

2. In assessing results the total day's excretion, rather than the unit value alone, should be considered.

3. Low diastase values definitely indicate nephritis as a rule; but not all nephritics (and notably pyelonephritics) have lowered values.

4. Not all types of pancreatic lesion cause excessive diastase output.

5. The test is of much value in dealing with toxamias of pregnancy and allied conditions.

The writer is indebted to his fellow-members of the staff of Swansea General Hospital for free access to their patients, on whom for the most part these estimations were performed, and particularly desires to acknowledge the assistance rendered in the making of estimations by his colleagues of the Beck Laboratory, Dr. Tris Fox and Dr. Mavis Grant.

References.-For usual technique of the test :-Cole, S. W. : Practical Physiological Chemistry, p. 362. Maclean, $\mathbf{H}$. : Diagnosis and Treatment of Renal Disease, p. 59. 1. WohlgeD. : Quarterly Jour. of Medicine, 1912-13, vi., 351. 3. Wallis, R. L. M. : St. Bartholomew's Hosp. Journal, May, 1921. 4. Walpole, G. S. : Biochem. Journal, vii., 6. 5. Palmer, W., and Henderson: Jour. of Biol. Chem., xxi., p. 37 (quoted
from Cole). 6. Löb: Biochem. Zeitschrift, 1912, xlvi., 125. B 2 